Lengua y Sociedad, revista de lingüística teórica y aplicada

Vol. 17, n. ${ }^{\circ}$ 1, Lima, enero-junio de 2018, pp. 161-174

https://doi.org/10.15381/lengsoc.v17i1.22369

\title{
El género discursivo Informe Final de Investigación en la educación superior ${ }^{1}$
}

\section{Final Research Report Discursive Genre in High Education}

\author{
María Mercedes Gonzales Rodríguez \\ Universidad Nacional Mayor de San Marcos \\ Departamento Académico de Lingüística \\ mgonzalesr@unmsm.edu.pe
}

\begin{abstract}
Resumen
El presente trabajo aborda el estudio de uno de los géneros discursivos empleados en la Escuela Profesional de Química de la UNMSM: el informe final de investigación. Se presentarán la definición de discurso académico y de discurso científico, las características del género, la estructuración textual, así como las marcas lingüísticas más relevantes.
\end{abstract}

Palabras clave: discurso, género discursivo, discurso académico, discurso científico, informe de investigación

\begin{abstract}
The present work addresses the study of one of the discursive genres used in the UNMSM Professional School of Chemistry: the final research report. The definition of academic discourse and scientific discourse, the characteristics of gender, textual structuring, as well as the most relevant linguistic marks will be presented.
\end{abstract}

Key words: discourse, discursive gender, academic discourse, scientific discourse, research report

1 Ponencia presentada al II Congreso Internacional y V Congreso Nacional de Lingüística y Educación «Félix Quesada Castillo». Departamento de Lingüística, Facultad de Letras y Ciencias Humanas de la UNMSM. Lima, 2016. 


\section{María Mercedes Gonzales Rodríguez}

\section{Introduccion}

Para abordar la definición de discurso, género discursivo y análisis textual, me enfocaré, en primer lugar, en algunos ejes temáticos desde la perspectiva de Foucault, Voloshinov, Bajtín y Charaudeau.

La unidad de discurso como proceso es el diálogo y como resultado es el enunciado según Voloshinov. El diálogo es el encuentro de al menos dos personas socialmente organizadas que interactúan a través de la palabra en enunciados. Si nos enfocamos en la palabra, esta es el producto de dos caras: una dirigida al hablante; la otra, al oyente (pág. 108). Entre ambos construyen una realidad a la cual refieren: intersubjetividad sujeta a muchos otros parámetros referidos a los otros elementos que se incluyan -teóricamente- en la concepción de comunicación (circunstancias inmediatas hasta las más generales). Famosa es la metáfora del autor sobre la palabra. «Una palabra es un puente tendido entre yo y otro. Si un extremo del puente se apoya en mí, entonces el otro se apoya en mi interlocutor. Una palabra es territorio compartido por el emisor y el receptor, por el hablante y su interlocutor» (pág. 108).

En ese «territorio compartido» (las $n$ circunstancias), el oyente se apropia de la palabra en la comprensión y el hablante la reactualiza en la producción. La palabra cobra vida en tanto toma sentido en el acto mismo de interacción social y no fuera de ella. Para Voloshinov, la palabra es ideológica por excelencia. Ideológica porque el sentido que toma la palabra expresa el mundo subjetivo de la persona frente al otro en las condiciones en las que opera la comunidad a la que pertenecen, y no fuera de ellas. Las diferencias de pareceres, de identidad social, psicológica, de género, de cultura, etc., todo se manifiesta en la palabra material (fonética y entonacional) y el medio que los circunda. Para el autor, la palabra está en constante reactualización de sus sentidos en el enunciado emitido y en la consecuente respuesta: característica generadora del lenguaje.

La conversación es la primera instancia del discurso: discurso primario para Bajtín. En esta práctica social, el ambiente es amistoso, asociado a conductas y enunciados libres: el género discursivo conversación espontánea. Se diferencia del discurso secundario porque, en esta, el diálogo se adecúa a las condiciones sociales de producción. Para Foucault serán enrarecimientos o procedimientos de control, selección y distribución del discurso. Lo cierto es que los enunciados toman formas concretas y estables según el lugar social en el que se enuncia: los géneros discursivos. 


\section{El género discursivo Informe Final de Investigación en la educación superior}

Según estas premisas me enfocaré en tres ejes temáticos para definir el discurso académico y el científico y en específico el género discursivo Informe Final de Investigación (IFI). Estos serán contrastados con el discurso primario para entender algunas dificultades de los estudiantes en la redacción.

\subsection{Las restricciones en la producción del discurso versus la espontaneidad.}

En el discurso académico, según Bernstein, las funciones sociales que los participantes asumen principalmente son, entre otros, el de profesor y alumno. El diálogo en el aula está definido por la sociedad pedagógica (instituciones educativas, UGEL, Minedu) en términos generales y el profesor según el curso en términos particulares. Los diálogos pedagógicos giran en torno a la enseñanza aprendizaje (qué, cómo enseñar, qué, cómo aprender, etc.) sobre la base de una relación asimétrica y jerarquizada por el conocimiento (el profesor es el portador del saber). La característica más específica y resaltante en el discurso académico es la evaluación que hay de por medio en las diversas prácticas sociales que se realizan en las aulas. La calificación, notas, es el producto de una serie de fuerzas sociales entre el docente y el estudiante que refleja las relaciones internas entre los participantes en el intercambio verbal: fuerzas de autoridad, control, negociaciones, transacciones, etc. Evidentemente, las prácticas didácticas y técnicas por parte del docente están asociadas a las sociales ya mencionadas y lo mismo se puede afirmar de los estilos de aprendizaje por parte del estudiante. La perspectiva de Bernstein es social (sociología del lenguaje) y le interesa al autor el poder y el control social ejercido por el docente en las prácticas pedagógicas a través del lenguaje de la sociedad inglesa.

El discurso científico es un diálogo entre investigadores cuyas prácticas sociales e interactivas se caracterizan por una tendencia a la simetría (las asimetrías son los casos de quema de libros o negación a la libertad de expresión o restricciones en la publicación por las editoriales, por ejemplo). Estos diálogos científicos se realizan en las distintas esferas de la sociedad donde se aplican las ciencias, sobre todo en el área de la economía (Lander, 2005). Lander, sociólogo y crítico de la epistemología de las ciencias, establece la relación entre la construcción del conocimiento de las ciencias y las necesidades de la sociedad, referidas estas no solo a los sectores más necesitados, sino sobre todo a los sectores inversionistas. Los discursos que emergen en esta situación justifican su quehacer científico ya sea se 
refiera a un sector u a otro de la sociedad. Para Lander, las ciencias, tanto teórica como aplicada está sesgada por los inversionistas sobre todo en países donde la universidad recibe subvención del sector privado; en este caso, la presión es mucha más imperativa; por lo tanto, los discursos manifiestan esas restricciones.

Los géneros discursivos son diferentes en ambos tipos de discursos. Evidentemente, los géneros discursivos académicos giran en torno a la enseñanza aprendizaje y sobre todo a la evaluación: prácticas, notas, exámenes, monografías, informes, etc. Tal es el caso del IFI: su presentación es un requisito para aprobar el curso. En cambio, los géneros discursivos científicos están publicados en algún medio de difusión; estos pueden ser ensayos, revistas, artículos periodísticos, artículos científicos, reseñas, libros, etc.

En el caso de la universidad, los diálogos académicos tienen la intención de que los estudiantes tomen voz propia en el trabajo intelectual. Así, la tesis es la «iniciación» del aprendiz en la sociedad del conocimiento y fin de la etapa académica. Mientras tanto, los discursos de los estudiantes van progresivamente hacia el ideal de un texto científico. Ese es también el caso del IFI.

El IFI presenta entonces doble intencionalidad y por ello está catalogado dentro del discurso académico-científico y considerado un género discursivo académico-científico. Parodi (2008) clasifica los géneros disciplinares dentro de un continuum entre los géneros académicos y los científicos porque no hay barreras claras sino fronteras difusas entre un género y otro. Puede haber entonces intersecciones entre géneros prototípicos. Este es el caso del IFI.

\subsection{Las condiciones de verdad versus la libertad de expresión}

Para Foucault, en las ciencias prevalece una voluntad histórica de saber que se evidencia en la oposición entre verdadero y falso. El autor plantea ciertos sistemas de exclusión que evitan la proliferación indefinida de los enunciados. Para el autor, en la actualidad,

En la actualidad, el estado de los avances científicos es cuestionado en cuanto a los valores de verdad y falsedad. La ciencia, que Lander llama neoliberal, ha invadido todos los espacios de la vida: las inversiones dirigen los estudios teóricos, metodológicos y tecnológicos (sin ampliarme en las consecuencias: los graves problemas de la contaminación, la pobreza no resuelta, etc.). El problema del mercantilismo afecta tanto a las humanidades como a las ciencias naturales.

\section{Lengua y Sociedad}


El género discursivo Informe Final de Investigación en la educación superior

En el discurso académico, prevalece el discurso referido. Voloshinov define el discurso referido como el discurso del otro, es decir, los enunciados son extraídos de su contexto social, local y temporal en que fue producido y son insertados en un nuevo diálogo dentro de un nuevo contexto. A nivel universitario, los estudiantes deben conocer los antecedentes del conocimiento; en ese sentido, retomar los discursos ajenos cobra valor en tanto se respeta la autoría; pero los estudiantes deben ser guiados a la producción del conocimiento. La meta, en esa carrera, es la tesis. El IFI es un paso previo a la obtención del galardón deseado. El discurso académico sufre restricciones en cuanto a las condiciones de verdad expuestas en la influencia de las economías sobre las ciencias.

\subsection{La manifestación de lo referido versus el ocultamiento de la subjetividad.}

En el discurso científico, el referente, el conocimiento sobre el mundo, cobra mayor valor en el enunciado que los coenunciadores en el diálogo. El enunciado, entonces, debe obviarlos. A este proceso de ocultamiento de la persona se le denomina despersonalización. Así, se construye la objetividad del conocimiento. Se omite la primera y segunda persona y por oposición aparece la tercera. Aristóteles planteaba que el «sujeto» de la oración no siempre es la persona, puede ser un objeto. De esta manera, el mundo cumple la función de primera persona: el mundo, la realidad, cobra vida en los enunciados. ¿Se pierde la dialogicidad? Si el «mundo» dialogara, hubiera respondido de alguna manera, o de repente ya respondió y nuestras creencias no lo escucha.

Lander (2005) califica las ciencias occidentales con muchos -istas: etnocentrista, mercantilista, sexista, mecanicista, y no falta racionalista y objetivista. En el último caso que nos concierne, critica la separación entre razón, cuerpo, subjetividad, «dimensiones constitutivas sin las cuales no puede darse cuenta de la vida» (pág. 1).

Retomamos a Voloshinov en el sentido de que toda palabra, enunciado, es ideológico. Las críticas de Lander lo demuestran. Los enunciados están construidos por personas socialmente organizadas que imprimen un punto de vista, una perspectiva que da lugar a la multiplicidad de sentidos; por esa razón, el lenguaje es polisémico por excelencia. Los enunciados en los diálogos científicos no escapan a esta realidad. Se plantea más bien una intersubjetividad que es más cercana a la premisa de que la ciencia no es infalible porque el conocimiento cambia según la 


\section{María Mercedes Gonzales Rodríguez}

época, los modelos teóricos, la perspectiva de análisis, etc. El discurso académico se enmarca dentro de esta perspectiva.

A continuación, pasemos a determinar la metodología y las características del género discursivo en cuestión.

\section{La metodología}

Para la presente investigación, se ha seleccionado un corpus que consiste en 10 informes finales de investigación que los estudiantes han presentado y sustentado en el curso de Investigación en Química B del semestre académico 2016-I. Los IFI se encuentran almacenados en la base de datos de la EP de Química para uso interno de los docentes mas no para uso externo, es decir, no son publicados. Se presenta a continuación el listado de los títulos de los trabajos de los estudiantes.

\begin{tabular}{c|l}
\hline 1 & Absorción por perlas de alginato dopadas con dimetil glioxima \\
\hline 2 & $\begin{array}{l}\text { Determinación de Vitaminas E en germen de trigo por espectrofotometría } \\
\text { Ultravioleta-Visible }\end{array}$ \\
\hline 3 & $\begin{array}{l}\text { Estudio de la remoción de trazas de plomo a partir de soluciones acuosas, usando como } \\
\text { sorbente material particulado de neumáticos fuera de uso }\end{array}$ \\
\hline 4 & $\begin{array}{l}\text { Estudio de los componentes químicos y evaluación de la actividad antioxidante del } \\
\text { fruto de lulo }\end{array}$ \\
\hline 5 & $\begin{array}{l}\text { Determinación y extracción del principio activo de la ambrosia arborescens (marco), } \\
\text { para su aplicación como analgésico tópico }\end{array}$ \\
\hline 6 & $\begin{array}{l}\text { Microencapsulación de Luteina mediante el método «spray drying» utilizando } \\
\text { quitosano y mucilago de chía como materiales encapsulantes }\end{array}$ \\
\hline 7 & $\begin{array}{l}\text { Estabilidad y sensibilidad de un electrodo de grafito y análogos modificado con } \\
\text { nanopartículas y coloides de plata quitosano en reemplazo del grafeno para la } \\
\text { cuantificación de dopamina }\end{array}$ \\
\hline 8 & $\begin{array}{l}\text { Estudio de los componentes de las pepas del camu camu, caracterización y utilización } \\
\text { de los desechos como biosorbente de cobalto }\end{array}$ \\
\hline 9 & $\begin{array}{l}\text { Desarrollo de un método rápido de comparación de los vinos tintos comerciales y } \\
\text { artesanales por técnicas instrumentales. }\end{array}$ \\
\hline 10 & $\begin{array}{l}\text { Síntesis y caracterización del complejo de cobre (II), [CuL }{ }_{2} \text { ] [HL=O-etil [(3-nitrofenil) } \\
\text { carbonil]carbamotioato] }\end{array}$ \\
\hline
\end{tabular}


El género discursivo Informe Final de Investigación en la educación superior

\section{Resultados y discusión}

Pasamos al nivel descriptivo del género discursivo del IFI.

El nivel de la situación de comunicación. El IFI es presentado por escrito en el curso de Investigación en Química B que se dicta en el último año de la carrera. Además, el estudiante debe sustentar su informe ante un jurado compuesto por el director (a) de la Escuela Profesional de Química y el docente del curso. Hay que resaltar que el estudiante elige al docente según el tema seleccionado. El curso, entonces, tiene $n$ docentes. En el curso, el estudiante debe demostrar, por un lado, un saber saber y un saber hacer por el cual el jurado emitirá un juicio sobre su competencia investigativa; por otro lado, el estudiante debe convencer al jurado de que los resultados de su investigación son verdaderos, por lo tanto, el jurado debe validarlos. Se evidencia la doble intencionalidad del IFI, la académica y la científica.

El nivel de la enunciación. El enunciador (Edor), el autor, establece una relación intersubjetiva de distanciamiento con respecto a sí mismo y al enunciatario (Erio), el lector docente. La imagen que el locutor construye es la de un Edor estudiante semiexperto en la especialidad que busca afianzarse como experto al presentar el producto de su experimento; para ello debe cumplir con todos los requisitos del proceso de investigación. El Erio docente es evocado como el experto en el tema que evaluará y validará los resultados.

Además, esta relación intersubjetiva de distanciamiento de los sujetos discursivos realza el hecho referido - el experimento-y lo Enunciado al respecto - el texto- produciendo un efecto de objetividad.

Esta distancia hace que no se manifiesten los sujetos discursivos en el texto y cobre mayor resalte lo Enunciado, el hecho acontecido. Los hechos, los acontecimientos del mundo referido, objeto de estudio de la disciplina, deben expresarse neutral e imparcialmente sin expresión alguna del apasionamiento. Tal punto de vista objetivo requiere para su manifestación lingüística de la omisión de las personas y un tono elevado de formalidad lexical y sintáctico. Se ampliará en el rubro del nivel textual.

En cuanto al discurso referido, es decir, incluir el discurso de otros en el enunciado, se evidencia en la citación de obras y en la intertextualidad. En el caso del IFI, la citación se manifiesta en la Introducción a través únicamente de las notaciones, como se observa en la Tabla 1. 
María Mercedes Gonzales Rodríguez

Tabla 1. Cuantificación de los autores de la bibliografía y la notación

\begin{tabular}{l|l|l|l|l} 
& Bibliografía & Cita directa & Cita indirecta & Notación \\
\hline 1 & 9 & 0 & 0 & 0 \\
\hline 2 & 10 & 0 & 0 & 9 \\
\hline 3 & 8 & 0 & 0 & 8 \\
\hline 4 & 8 & 0 & 0 & 0 \\
\hline 5 & 4 & 0 & 0 & 0 \\
\hline 6 & 7 & 0 & 0 & 0 \\
\hline 7 & 14 & 0 & 0 & 8 \\
\hline 8 & 6 & 0 & 1 & 0 \\
\hline 9 & 9 & 0 & 0 & 2 \\
\hline 10 & 12 & 0 & 0 & 12 \\
\hline
\end{tabular}

En cuanto a la intertextualidad, esta se evidencia a través de las notaciones que remiten a la bibliografía empleada y aparecen en la Introducción. Las notaciones llevan un orden correlativo; sin embargo, al final del trabajo, el título empleado es bibliografía. Los números de las notaciones se repiten y en algunos trabajos el orden es indistinto al presentado en la bibliografía. En 3, de los 13 párrafos de la Introducción, las notaciones aparecen al final de cada uno de los 8 primeros párrafos; indica que la idea del párrafo la ha obtenida del autor numerado en la bibliografía.

Con respecto la polifonía, en el IFI no hay presentación de voces de trabajos previos con las cuales dialogar sobre el tema presentado. Como el texto no es dialógico, podemos decir que no es argumentativo porque no hay discusión alguna. Es más explicativo del experimento en su conjunto.

En relación a la objetividad, si bien la identidad del Edor no se manifiesta a lo largo del texto, por ejemplo, el uso de la primera persona singular, se recurre a otros procedimientos como muy bien lo expone Calsamiglia y Tusón: la primera persona plural, por ejemplo nosotros, el verbo en tercera persona plural, por ejemplo probamos, la referencia léxica, por ejemplo como investigador, la autorrreferencia, por ejemplo Gamarra (tomando el nombre de uno de los autores de los IFI). A continuación, se presentan algunos mecanismos de la omisión de la persona en los enunciados. 
El género discursivo Informe Final de Investigación en la educación superior

El se impersonal.

El estudio de la capacidad de sorción del material particulado de los neumáticos fuera de uso (NFU), se realizó mediante una isoterma de sorción. (3, pág. 1)

El se pasivo

De este modo se realizará la extracción de este, con el método respectivo, dependiendo de los resultados del screening fitoquímico... (5, pág. 3)

La voz pasiva

Ha sido sintetizado el complejo de cobre(II) a partir de un derivado de aciltiourea. (10, pág. 1)

El verbo impersonal hay

Actualmente hay diferentes métodos para su determinación como los colorimétricos, que son usados para fines prácticos en la enseñanza universitaria... (2, pág. 3)

Los verbos en infinitivo

Para estudiar la capacidad de competencia del alginato y el DMG para la captación de cobre... (1, pág. 10)

Los verbos en gerundio

Las diversas formas de utilización de cobre y la contaminación que genera este metal conlleva a buscar soluciones considerando como una alternativa los absorbentes baratos y más eficaces como son los biopolímeros... (1, pág. 4) Los verbos en participio

Dejar reposar unos minutos luego separar la capa etérea en un vaso previamente pesado. (4, pág. 8 )

La nominalización

Para el estudio de la cinética del proceso de adsorción... (1, pág. 10)

Si bien se omite la persona, la manifestación de la subjetividad del hablante se manifiesta a través de otros mecanismos como la modalización. Esta consiste en evidenciar qué perspectiva o punto de vista tiene sobre lo que enuncia. La modalización puede ser epistémica o evidencial.

La modalidad epistémica. Se refiere «al grado de compromiso que el hablante tiene en relación con la verdad de la proposición que tales aserciones indican» (Ferrari ,2009; referido en Álvarez, 2013) Se reconocen dos tipos: la asertiva y la no asertiva.

Modalidad epistémica asertiva. La certeza está expresada no de manera léxica sino sintáctica. El empleo de las oraciones aseverativas y con orden sintáctico canónico (SVO) indica certeza. 


\section{María Mercedes Gonzales Rodríguez}

El parámetro de polifenoles totales no tiene un valor mínimo ni uno máximo, pero presentan un valor promedio de polifenoles totales de los vinos tintos mundiales, el cual es de 2500 mg ácido gálico/L³. (9, pág. 7)

- Modalidad epistémica no asertiva. Se manifiesta de las siguientes maneras:

Probabilidad. Se expresa con verbos.

...teniendo como comparación el área superficial del carbón activado $(500 \mathrm{~m} 2 / \mathrm{g})$, se podría esperar una baja capacidad de sorción del polvo de neumático fuera de uso. (3, pág. 15)

Posibilidad. Se manifiesta con adjetivos o adverbios.

Es muy posible que los vinos artesanales contengan mayor contenido de polifenoles debido a que siguen un procedimiento no industrializado... (9, pág. 15)

Este posiblemente es el motivo por el que se encuentra mayor cantidad de etanol en los vinos artesanales. (9, pág. 16)

Expectativa para luego ser confirmada. Se expresa con verbos.

Como era de esperarse, al no tener un control de los procesos artesanales de preparación de esta bebida era de suponer que el contenido de etano podría estar por encima del permitido y los resultados confirman dicha suposición. (9, pág. 16)

Obligación. Se manifiesta con verbos.

No es que sea perjudicial el contenido alcohólico encontrado en los vinos artesanales, pero sí es importante que cumplan ciertas normas... (9, pág. 16)

Se debe tener en cuenta que para la obtención del mucílago de chía debe ser muy diluido para evitar que precipite... (6, pág. 20)

La modalidad evidencial. Se refiere a la «expresión de la forma como el conocimiento ha sido adquirido» (López, 2005)

Presentación de información. Se expresa con verbos.

Según muestra la gráfica 1 al realizar el análisis de los datos se observa una correlación de $0,9834 \ldots$ (3, pág. 11)

Por otro lado, según el espectro IR (ver apéndice) de los desechos de la pepa del camu camu, se puede observar según la tabla 2 que los grupos funcionales presentes es un $\mathrm{OH}, \mathrm{C}=c \mathrm{YC}-\mathrm{O} \ldots$ (8, pág. 12)

Podemos ver que en la parte UV se ha distorcionado... (6, pág. 24)

Las medidas espectrocópicas inician con la obtención de los espectros de absorción, muy útiles pues nos permiten visualizar los picos máximos de absorción de las sustancias... (6, pág. 22) 
El género discursivo Informe Final de Investigación en la educación superior

De inducción y deducción. Se expresa con verbos.

... la contaminación que genera este metal conlleva a buscar soluciones considerando como una alternativa los absorbentes baratos... (1, pág. 4)

El porcentaje de concentración remanente indica cuanto del contaminante queda en la solución muestra... (3, pág. 14)

Este resultado se obtiene aplicando la ecuación 2,... (3, pág. 14)

De confirmación con adverbios.

...efectivamente se observó una adsorción por parte del filtro sinterizado del orden de 0,212 $m g / L \ldots$ (3, pág. 12)

De certeza con sustantivos.

Esto permite tener la seguridad de producir la reducción del $\mathrm{AgNO}_{3}$ y no la oxidación. (7, pág. 10)

El nivel del texto. La EP de Química cuenta con una guía para la elaboración del IFI. En ella se plantean las partes que debe contener el informe, las normas de forma como manera de presentar la carátula, las entrelíneas, los márgenes, tamaño de la fuente, etc.

La organización superestructural del texto que se exige es como sigue: resumen, abstract en inglés, introducción, objetivos, parte experimental, resultados y discusión, conclusiones, bibliografía, anexos. El IFI no presenta marco teórico ni hipótesis. Como se mencionó, la secuencia textual es explicativa. El estudiante debe plantear los objetivos, explicar qué métodos y técnicas empleó, cómo los aplicó y qué resultados obtuvo sin discusiones.

En cuanto al léxico, este es el de la especialidad. Se caracteriza por la precisión, es decir, se evita la ambigüedad, por la monosemia, a cada unidad léxica le corresponde un concepto y no debe presentar sinonimia; por último, por la neutralidad emocional, no se encuentra términos asociados a valores emocionales.

Algunas dificultades encontradas en la redacción de los IFI:

1. En cuanto a los objetivos, se ha encontrado que, en algunos casos, estos no están separados sino aglomerados.

Desarrollar un método espectrofotométrico para la determinación de vitamina $E$ en germen de trigo, cuantificarlo de manera rápida, sencilla, confiable y posteriormente aplicarlo como control de calidad en productos a base de este alimento como también en productos con concentraciones detectables de vitamina E. (2, pág. 3) 
Debió haberse formulado tres objetivos y no uno solo porque se observa claramente que se está refiriendo a tres procesos que van en continuidad uno tras otro.

2. En la parte experimental, generalmente se presentan figuras numeradas que constatan cómo se realizó el experimento; sin embargo, se ha encontrado algunos casos en que las figuras no están insertas en la presentación de los materiales ni en la explicación de los procedimientos empleados. Indica información desvinculada del texto.

3. En la parte experimental se debe presentar el (los) procedimiento(s) empleado(s); sin embargo, se ha encontrado que no hay una continuidad en los pasos a seguir.

4. En la presentación de los resultados, estos se realizan en cuadros estadísticos, tablas, gráficos o figuras. Se encuentra que estos no están insertos en la parte correspondiente a la discusión de resultados. La información gráfica está desvinculada del texto.

5. En la presentación de los resultados, hay descripción de los procesos. Se encuentra imprecisión léxica y quiebres lógicos.

A 5 minutos del encendido del equipo, al medir la energía de la lámpara, resulta un valor de 2(bajo), indicando la necesidad de esperar que se caliente la lámpara de plomo.

Debe decirse «se obtiene».

A los 15 minutos se midió la energía de la lámpara y resultando 25 , el cual sigue siendo considerado bajo, para tener una buena eficiencia de detección de la lámpara; sin embargo, se observa que el valor no aumenta al dejarla más tiempo, por lo cual se inicia las corridas... (3, pág. 10)

Debe decirse «se obtuvo». El conector «sin embargo» está mal empleado porque por el contexto no hay una relación de oposición entre la información precedente y la que sigue. Hay por lo tanto quiebre lógico.

6. Falta uso estándar de los conectores que expresan pertenencia en la frase nominal.

[...] y así aumentar su estabilidad la molécula. (8, pág. 12)

7. Se encuentra uso redundante de los conectores (subrayados para resaltarlos) Se pesa 0,5; 1,0; 1,5 y 2, o g aproximadamente del molido de los desechos y se coloca en vasos de $1000 \mathrm{ML}$ y se adiciona $100 \mathrm{~mL}$ de solución de CoCl2 y se lleva a $300 \mathrm{~mL}$ con agua destilada. (8, pág. 9).

Al agregar $\mathrm{HCI} 2 \mathrm{~N}$, se observó que algunos burbujeos, que nos indica la liberación de $\mathrm{CO}_{2}$ producto de la reacción del $\mathrm{CaCO}_{3}$ y HCI. (6, pág. 15) 
El género discursivo Informe Final de Investigación en la educación superior

8. En los anexos se añaden figuras, cuadros, tablas pero no hay referencia a ellos en la discusión de los resultados.

\section{CONCLUSIONES}

El IFI es un género discursivo académico-científico porque cumple con las finalidades educativas del centro universitario que es el demostrar competencia investigativa y cumple con las exigencias científicas de corte experimental.

Se eluden los antecedentes en los IFI y con ello se obvian las voces, la polifonía. Tampoco se encuentran discusiones argumentativas, es decir, no hay dialogismo. La intertextualidad es tangencial, en otras palabras, aparece solo el listado bibliográfico con notaciones sin recurrir a las citas, al discurso referido.

Por estas recurrencias en los IFI, se puede inferir que es una norma que la institución establece; son consideras restricciones en la producción del género discursivo.

La falta de antecedentes hace suponer que el tema presentado es original por el asesoramiento del docente experto en la materia. Como no hay dialogismo, la secuencia textual es explicativa. El estudiante debe probar a través de explicaciones un saber hacer experimentos y un saber obtener resultados. Las conclusiones son pues pragmáticas.

En realidad, el IFI no es una tesis; pero exige que el estudiante pruebe su competencia sobre todo en la metodología experimental y con ello evidencia una influencia de los requerimientos de la época actual como es el avance tecnológico.

En cuanto a la objetividad, se cumple con la norma de omitir a las personas con los mecanismos de despersonalización; sin embargo, se manifiesta la subjetividad a través de las modalizaciones como la epistémica asertiva, y la evidencialidad de presentación de información, de certeza, de confirmación.

En cuanto al texto, el IFI cumple con las normas establecidas en un artículo de investigación en cuanto la superestructura sin ser extenso en su desarrollo. Se encuentran dificultades en la conexión de la información gráfica y en el nivel microestructural. 


\section{María Mercedes Gonzales Rodríguez}

\section{Bibliografía}

Álvarez, F. (2013). La despersonalización en el discurso académico (Tesis doctoral). Recuperada de Biblioteca Digital de la Universidad de Alcalá. (https://ebuah. uah.es/dspace/handle/10017/20049).

Bajtín, M. (1982). Estética de la creación verbal. Madrid: Siglo XXI.

Benveniste, E. (1977). El aparato formal de la enunciación. En Problemas de lingüística general II. México: Siglo XXI.

Bernstein, B. (1993). La estructura del discurso pedagógico. Clases, código y control (Vol. IV). Madrid: Morata.

Charaudeau, P. (agosto, 1995). Análisis del discurso: Lectura y Análisis de Textos. Lenguaje, 22.

Foucault, M. (2004). El orden del discurso. España: Tusquets.

Lander, E. (2005). La ciencia neoliberal. Revista Venezolana de Economía y Ciencias Sociales, 11(2).

Parodi, G. (2008). Géneros discursivos y lengua escrita: Propuesta de una concepción integral desde una perspectiva sociocognitiva. Letras, 51(80).

Shiro, M., Charaudeau, P., \& Granato, L. (2012). Los géneros discursivos desde múltiples perspectivas: teoría y análisis. Madrid: Iberoamericana.

Voloshinov, V. (1976). El signo ideológico y la filosofía del lenguaje. Buenos Aires: Nueva Visión. 